\title{
Type of Floral Product Purchased and Demographic Characteristics and Floral Knowledge of Consumers
}

\author{
Bridget K. Behe ${ }^{1}$ and Dennis J. Wolnick ${ }^{2}$ \\ Department of Horticulture, The Pennsylvania State University, \\ University Park, PA 16802
}

Additional index words. floral marketing, discriminant analysis, consumer behavior

\begin{abstract}
We determined the influence of demographic characteristics and floral knowledge (measured as product experience) on the type of floral product purchased. A sample of 401 Pennsylvania residents was divided into fresh flower and flowering plant consumer segments. Results of discriminant analyses showed the two segments were moderately distinct. Purchasers of fresh flowers were younger and more likely employed outside the home than those who purchased flowering plants, but the latter had more blooming plants in their homes than did consumers of fresh flowers. Consumers of flowering plants and of fresh flowers did not differ in their level of floral knowledge or demographic characteristics. Minor differences were found between the two segments that were not substantial enough to justify distinct marketing strategies.
\end{abstract}

Demographic characteristics are nearly always included in consumer research. Such characteristics are attributes of individuals that help to identify their socio-economic status, such as age, education, gender, and income. These variables are often used in market segmentation studies (Dickson and Ginter, 1987; Market Facts, 1985; Miller, 1977) because they are easy to measure and have a relatively straightforward empirical link to their abstract constructs.

Past floral consumer behavior studies have separated purchasers from nonpurchasers based upon differences in demographic characteristics (Demby, 1973). Gender has been commonly used as a basis of segmentation, but few differences in floral purchasing have been found between these two segments (Behe and Wolnick, 1988; Market Facts, 1985).

\footnotetext{
Received for publication 8 Dec. 1989. We thank the Pennsylvania Florists' Assn. for their generous funding of this research. The cost of publishing this paper was defrayed in part by the payment of page charges. Under postal regulations, this paper therefore must be hereby marked advertisement solely to indicate this fact.

'Assistant Professor. Current address: Dept. of Horticulture, Auburn Univ., Auburn, AL 368495408.

${ }^{2}$ Associate Professor.
}

Income has a relatively strong link to floral buying behavior (Market Facts, 1985). These studies have provided evidence that the number of floral purchases increases as income increases. Age and education have not often been used as predictors, most likely due to the high correlation that likely exists with income. Income is often considered the best predictor from this group.

Consumer knowledge affects purchases of some products (Sujan, 1985). Market Facts (1985) identified a series of phases through which consumers progress as their floral purchases increase. Consumers progress from flowering plant to fresh flower purchases. Blooming plants were often purchased as a consumer was beginning to acquire knowledge about flowers and plants. After some time, the number and amount of floral purchases increased, and so did the number of fresh flower purchases. Market Facts suggested some degree of floral knowledge was acquired before fresh flowers were purchased. Age also appeared to influence the type of product purchased. Older consumers purchased more flowering plants than fresh flowers. Education was not included in the model.

The objective of this research was to determine the influence of demographic char- acteristics and floral knowledge (measured as product experience) on the type of floral product purchased.

Sample selection. In Mar. 1987, 401 Pennsylvania floral consumers were interviewed by a professional telemarketing firm over 3 weeks. The sample was developed in six steps: stratification by geographic region (urban and rural), selection of telephone directories, random selection of names from each telephone directory, stratification by gender, exclusion of nonpurchasers, and exclusion of minors (under 18 years) from the sample.

After the questionnaire was developed and tested, a minimum number of 400 respondents was determined to be necessary for statistical purposes. Further, the sample was divided into two groups, representing urban and rural populations in Pennsylvania. Three hundred urban and 100 rural residents were included to ensure an adequate sample for regional comparisons. Ten telephone directories were selected at random from a list of Pennsylvania directories. Interviewers selected a prescribed number of respondents from each directory. The sample was further stratified by gender to include a minimum of 100 men to ensure a large enough sample size for comparisons. When the quota for men from each directory had been achieved, the interviewer surveyed a female from each of the next households called. Only fresh flower and flowering plant buyers participated. Individuals who had not purchased a floral product in the previous year were eliminated from the sample; no record was kept of that number.

Variables included in the analysis. Information on 106 variables was collected during each interview. Five variables about floral knowledge and five demographic characteristics were used in the analysis (Table 1).

Consumers were divided into two groups based on the total number and types of floral purchases made in the previous year. Purchases were classified as fresh flowers or flowering plants. Fresh flower purchases included floral arrangements, corsages, single stems of fresh flowers, or the purchase of prepacked bunches or bouquets. Although economically important, purchases of flowering plants excluded foliage plants and bedding plants because they were considered very different products from fresh flowers and flowering plants. Interviewees who had made 
more than half of their total purchases as fresh flower products were classified as fresh flower consumers. Purchasers who had made more than half of their total purchases as flowering plants were classified as flowering plant consumers.

Thirty-two consumers had an equal number of fresh flower and flowering plant purchases and were excluded from the analysis since they could not be classified as belonging exclusively to one group. $t$ tests of groups means were conducted on 369 responses. Eighty-nine additional respondents were excluded from the discriminant analysis because data were missing for one or more variables.

Discriminant analysis. Discriminant analysis is a statistical method that produces functions describing the relationship between two or more mutually exclusive groups (Bull and Dormer, 1987; Dillon and Goldstein, 1984; Klecka, 1981; Morrison, 1969; Norusis, 1985). For purposes of this study, discriminant analysis was used to explain differences between two floral consumer groups without prediction of additional cases into groups.

The standardized discriminant function coefficients can be useful in describing the discriminant function. Coefficients with relatively larger standardized values explain more variance; thus, they are more closely related to the function than variables with smaller values. AH coefficients are used when the group means (group centroids) are calculated.

Consumers of flowering plants had an average of five more blooming plants in their homes than fresh flower consumers, and the former were older and less likely to be employed outside the home (Table 1). Otherwise, no differences were observed between the two groups.

Multivariate results (Table 2) showed the standardized discriminant function coefficients that comprise the discriminant equation. The equation was statistically significant. The standardized canonical correlation coefficients (Table 2, function 1) indicate the direction and strength of the relationship between the variable for the first discriminant function. The number of blooming plants owned was the most strongly and positively related variable to the discriminant function, followed by age. The presence of fresh flowers in the home was strongly yet negatively related to the discriminant function. The discriminant function was labeled as a flowering plant to fresh flower continuum with blooming plants in the home at the positive end and fresh flowers in the home at the negative end.

Since there was no difference between fresh flower and flowering plant consumers for 1986 household income, and this variable was missing for 58 respondents (17\% of the sample), a second discriminant analysis was conducted without the income variable. Multivariate results from the second discriminant analysis (Table 2, column 2 ) were very similar to those of the first discriminant analysis. Thus, consumers who did not re- spond to the income question randomly excluded themselves from the study.

The discriminant function produced from the second analysis was also significant. The canonical coefficient of the function changed little in the magnitude from the first analysis to the second. The Wilk's lambda was also relatively constant. No sign changes were observed for the standardized canonical coefficients, and only slight increases in magnitude were noted. For descriptive purposes, the three largest coefficients were examined (Rummel, 1970). The number of blooming plants in the home and respondents' ages were most strongly and positively related to the function. The presence of fresh flowers in the home was again strongly and negatively related to the function.

This function was also labeled as a continuum of fresh flowers to flowering plants in the home, with higher values indicating a

Table 1. Comparison of cut flower and potted plant consumer segment group means and standard deviations.

\begin{tabular}{lccc}
\hline \hline & \multicolumn{2}{c}{ Consumer group } & \\
\cline { 2 - 3 } Variable & Cut flower & Potted plant & $\begin{array}{c}\text { Significance } \\
\text { level }\end{array}$ \\
\hline No. magazine articles read & 1.6 & 1.2 & 0.495 \\
$\left(\mathrm{n}_{1}=202, \mathrm{n}_{2}=153\right)^{\mathrm{y}}$ & $(7.37)$ & $(2.07)$ & \\
No. books owned & 2.1 & 2.7 & 0.244 \\
$\quad\left(\mathrm{n}_{1}=202, \mathrm{n}_{2}=153\right)$ & $(4.60)$ & $(5.07)$ & \\
No. blooming plants owned & 3.4 & 7.7 & $0.001^{*}$ \\
$\left(\mathrm{n}_{1}=202, \mathrm{n}_{2}=153\right)$ & $(5.46)$ & $(16.22)$ & \\
Proportion of consumers with cut flowers in the & 0.3 & 0.2 & 0.078 \\
home $\left(\mathrm{n}_{1}=200, \mathrm{n}_{2}=153\right)$ & $(0.43)$ & $(0.38)$ & \\
Floral knowledge rating & 4.4 & 4.9 & 0.109 \\
$\quad\left(\mathrm{n}_{1}=202, \mathrm{n}_{2}=153\right)$ & $(2.29)$ & $(3.63)$ & \\
Education (years) & 13.8 & 13.4 & 0.077 \\
$\quad\left(\mathrm{n}_{1}=200, \mathrm{n}_{2}=153\right)$ & $(2.26)$ & $(2.24)$ & \\
Age (years) & 42.2 & 48.4 & $0.001^{*}$ \\
$\quad\left(\mathrm{n}_{1}=195, \mathrm{n}_{2}=147\right)$ & $(15.8)$ & $(16.3)$ & \\
Proportion of consumers employed outside the & 0.6 & 0.4 & $0.001^{*}$ \\
home ( $\left.\mathrm{n}_{1}=199, \mathrm{n}_{2}=151\right)$ & $(0.49)$ & $(0.49)$ & \\
1986 household income (thousand dollars) & 27.8 & 28.1 & 0.830 \\
$\quad\left(\mathrm{n}_{1}=162, \mathrm{n}_{2}=122\right)$ & $(11.4)$ & $(11.6)$ & \\
Proportion of females & 0.7 & 0.8 & 0.104 \\
$\left(\mathrm{n}_{1}=202, \mathrm{n}_{2}=153\right)$ & $(0.46)$ & $(0.41)$ & \\
\hline
\end{tabular}

${ }^{z}$ Means for the consumer segments.

'Sample sizes for cut flower and potted plant segments.

*Significant at $\alpha<0.05$.

Table 2. Standardized discriminant function coefficients for two discriminant functions separating cut flower and potted plant consumer segments. High + or - values indicate a strong relationship.

\begin{tabular}{lcc}
\hline \hline & \multicolumn{2}{c}{$\begin{array}{c}\text { Standardized discriminant } \\
\text { function coefficients }\end{array}$} \\
\cline { 2 - 3 } Variables & Function $1^{z}$ & Function $2^{y}$ \\
\hline No. magazine articles read & 0.16 & -0.11 \\
No. books owned & 0.01 & 0.16 \\
No. blooming plants owned & 0.58 & 0.66 \\
Proportion of consumers with cut flowers in the home & -0.32 & -0.31 \\
Floral knowledge rating & 0.13 & -0.03 \\
Education (years) & -0.13 & -0.12 \\
Age (years) & 0.50 & 0.44 \\
Proportion of consumers employed outside the home & 0.28 & -0.25 \\
Annual household income (thousands) & 0.21 & 0 Omitted \\
Proportion of females & 0.11 & 0.17 \\
\hline
\end{tabular}

${ }^{2}$ First discriminant analysis produced: $\chi^{2}$ value $=27.37$, significance $=0.0023$. Canonical correlation $=0.31$; Wilks lambda $=0.90$; Group centroids: Cut flower consumers, -0.28 , Potted plant consumers, 0.37 .

YSecond discriminant analysis omitted the household income variable and produced: $\chi^{2}$ value $=31.16$, significance $=0.0003$. Canonical correlation $=0.30$; Wilks lambda $=0.91$; Group centroids: Cut flower consumers, -0.27 , Potted plant consumers, 0.36 . 
product) determined which type of consumer the respondent was.

These two consumer segments were compared on two distinct dimensions: floral knowledge and demographic characteristics. Only one discriminant function can be produced from an analysis with two groups. Thus, one of the two dimensions was likely to emerge as being more important in distinguishing between the two segments. Experience appeared to be more useful in separating these consumer groups than demographic characteristics, although age was a discriminating factor. Older consumers purchased more plants and had more plants in their homes during the interview than did fresh flower consumers. This result is similar to the results presented in the Market Facts (1985) study.

Flowering plant consumers, who tend to be older, may have acquired more floral knowledge (experience) through other lifelong experiences, as they may have observed others cultivating plants in their homes and gardens. Perhaps they had more blooming plants in their homes at the time of the interview because they had the knowledge and time to maintain them. The evidence here seems to be in conflict with a conclusion drawn from the Market Facts (1985) data suggesting that consumers with little floral knowledge purchase plants for their own use, and then progress to fresh flower purchases as experience is gained.

Income appeared to have no effect in differentiating between fresh flower and flowering plant consumer segments. The income effect reported in other studies was not observed here.

Closely related to income are education and employment. While the number of years of education did not contribute significantly to differentiating between these two consumer segments, employment outside the home did. Leisure time might have an important influence here in the selection of fresh flowers over blooming plants. Fresh flowers may be selected when less time is available to care for floral products.

The discriminant function that differen- tiated fresh flower consumers and flowering plant consumers separated the group centroids from -0.27 to 0.36 . Three univariate statistical differences were found, but these differences do not appear to be substantial enough to justify developing separate marketing strategies.

Levitt (1988) addressed a concern of an increasing number of market segments that may help explain why we found few differences. Levitt (1988) suggested that heterogeneity is thriving. He described more differences for one individual consumer's behavior rather than differences in behavior between groups of consumers. Consumer segments seem no longer discrete, but are overlapping. He concluded: "We live suddenly in a world of segment simultaneity, the new world of the heteroconsumer. What's new is not the multiplication of segments but rather the pluralization of consumption".

He suggested that in different situations, consumers can be classified into different consumer segments. The segments are discrete, but consumers can be in more than one segment over time. Regarding floral products, Levitt's (1988) theory implies that in one situation a consumer would purchase a fresh flower (e.g., a boutonniere) and in another situation would purchase a blooming plant (e.g., as a centerpiece). Thus, it may not be consumer characteristics (demographic characteristics or floral knowledge) but rather the situation that dictates which product will be purchased. Another issue that may affect the purchase of fresh flowers vs. flowering plants is the time pressure under which the consumer is placed. The selection of the type of floral product may be reduced to the product assortment of the retail outlet.

Finally, the reason for finding so few differences between consumer segments may lie in the construct of floral knowledge. Few differences may have been found because the variables neither adequately nor accurately measured floral knowledge and experience. Additional variables could be included in the construct to capture the influence of gardening, flower arranging, parental knowledge, and use of flowers and plants. Perhaps these dimensions would enhance the measurement of floral knowledge and experience.

Fresh flower and flowering plant consumers, at least as defined in this research study, do not appear to be viable market segments, although knowning that these two groups are not distinct is useful information in itself. A segmentation based upon the type of product purchased would most likely not reach different groups of consumers. Future efforts should be focused on the influence of the reason for the purchase on the type of floral product purchased.

\section{Literature Cited}

Behe, B.K. and D.W. Wolnick. 1988. A purchasing profile. Soc. Amer. Florists. Apr. (5):3035.

Bull, S.B. and A. Donner. 1987. The efficiency of multinominal logistic regression compared with multiple group discriminant analysis. J. Amer. Stat. Assn. 82(Dec.)400:1118-1122.

Demby, E. 1973. A psychographic study of the market for flowers. Amer. Florists Marketing Council. Alexandria, Va.

Dickson, P.R. and J.L. Ginter. 1987. Market segmentation, product differentiation, and marketing strategy. J. Marketing 51(2):1-10.

Dillon, W.R, and M. Goldstein. 1984. Multivariate analysis: methods and applications. Wiley, New York.

Klecka, W.R. 1981. Discriminant analysis. Quantitative applications in the social sciences series. Sage Publications, Beverly Hills, Calif.

Levitt, T. 1988. The pluralization of consumption. Harvard Business Rev. 88(3):7-8.

Market Facts, Inc. 1985. Floral marketing report. Market Facts, Washington, D.C.

Miller, M.N. 1977. Consumer preferences for and attitudes toward cut flower items in supermarkets. M.S. Thesis, Purdue Univ., West Lafayette, Ind.

Morrison, D.G. 1969. On the interpretation of discriminant analysis. J. Marketing Res. 6:156163.

Norusis, M.J. 1985. SPSS ${ }^{\mathrm{x}}$ advanced statistics guide. McGraw Hill, Chicago.

Rummel, R.J. 1970. Applied factor analysis. Northwestern Univ. Evanston, Ill. p. 477.

Sujan, M. 1985. Consumer knowledge: Effects on evaluation strategies mediating consumer judgments. J. Consumer Res. 12:31-46. 